\title{
TIME AGGREGATION AND THE CONTRADICTIONS WITH CAUSAL RELATIONSHIPS: CAN ECONOMIC THEORY COME TO THE RESCUE?
}

\author{
R Gupta* and K Komen
}

Abstract
The literature on causality takes contradictory stands on the
direction of causal relationships based on whether one uses
temporally aggregated or systematically sampled data. As an
example, using the relationship between a nominal target and the
instrument used to achieve it, we show that one can fall back upon
the data in itself, and analyse it from the perspective of economic
theory, not only as a source of second opinion to econometric
theories and Monte Carlo simulations, but also to draw proper
conclusions regarding the form of the causal relationship that might
be actually existing in the data.

\section{Introduction}

In a series of related papers, Abeysinghe and Gulasekaran (2002 and 2004a, 2004b) and Gulasekaran (2004), based on econometric theory and subsequently on Monte Carlo simulations, point out that systematic sampling of two co-integrated series tend to induce spurious causality, even if they have been differenced prior to being used. Specifically, the studies show that in the presence of unit roots, systematic sampling might actually indicate bi-directional causality, when in reality there exists only unidirectional causality between the variables. This result is opposite to what has been known in the literature thus far concerning causal relationships between variables. Prior to this finding, papers of Sims (1971), Tiao and Wei (1976), Wei (1982), Cunningham and Vilasuso (1995) and Cunningham and Vilasuso (1997) have tended to suggest that in case of stationary series, it is systematic sampling, and not temporally aggregated data, that preserves the true direction of Granger causality. However, none of the latter set of papers investigated the role cointegration might have in influencing causality between variables, and, hence, were possibly flawed in drawing their conclusions regarding causal relationships with temporally aggregated data. In other words, the conclusions of these studies are only true if the series are merely stationary. However, if the series are co-integrated, it is advisable to move into an Error

\footnotetext{
* Department of Economics, University of Pretoria, Pretoria 0002, Republic of South Africa. Email: Rangan.Gupta@up.ac.za
} 
Correction framework to test for Granger causality, since causality should emerge, at least in one direction, from the fact that the variables have a common trend, and thus, the current change in a specific variable should be partly the fallout of that variable moving in accordance with the trend value of the other variable. ${ }^{1}$ In this regard, it is important to draw attention to the study by Mamingi (1996), in which the author, using Monte Carlo experiments, indicates that Granger causality tests in Error Correction Models (ECMs) with temporally aggregated data is flawed, but with systematic sampling, for variables that are co-integrated, Granger causality distortion is largely absent.

Note, the economic intuition behind the technical details of the effect of time aggregation on Granger causality can be explained as follows: Let us consider the general case of Vector Autoregressive (VAR) model of order k, VAR(k). As the level of temporal aggregation increases, a stationary $\operatorname{VAR}(\mathrm{k})$ process might tend towards $\operatorname{VAR}(0)$ by absorbing all causal information into contemporaneous links, even when such correlations are absent in the non-aggregate process. Moreover, as temporal aggregation increases contemporaneous correlations may be all that is left between the series. As a result, one may not find Granger-causality at all with temporally aggregated data, which is however, not the case with systematic sampling of stationary data. On the other hand, a co-integrated $\operatorname{VAR}(\mathrm{p})$ process cannot shrink below VAR(1), simply because of the presence of unit roots. ${ }^{2}$ Thus, some of the adjustment coefficients of the error correction model will remain nonzero regardless of the level of temporal aggregation. Therefore, weak exogeneity under cointegration helps, not only in contemporaneous conditioning, but also in Granger causality inference.

In such a backdrop, we try and assay, if the possible contradiction that might arise regarding the direction of causality depending on the two alternative ways of processing the data can be resolved by falling back on the economic theory that possibly governs the relationship between these two variables. Though it is generally the other way round, i.e., researchers tend to empirically test economic theory, but given that the contradiction has emerged in the econometric theory itself, we propose that though there is no gainsaying the importance of econometric theory and simulations, the researcher should perhaps, learn to look beyond them in drawing the appropriate conclusions by understanding the underlying economic process that might be determining the movements of these two variables. To validate our point we look at the relationship between a nominal target and the monetary instrument used to achieve this target. Understandably, and ideally if the monetary policy framework is in place correctly, the relationship should be bidirectional, since a change in the target, say due to external shocks or changes in expectations, would cause the monetary authority to adjust its instrument to

\footnotetext{
${ }^{1}$ See Section 2 for further details.

${ }^{2}$ One must realize that if $\theta_{1}, \theta_{2}, \ldots \ldots . \theta_{\mathrm{n}}$ are the roots of the non-aggregated autoregressive process, then $\theta_{1}^{\mathrm{m}}, \theta_{2}^{\mathrm{m}}, \ldots \ldots \theta_{\mathrm{n}}^{\mathrm{m}}$ are the roots of the aggregated process, where $m$ is the order of aggregation (Abeysinghe and Gulasekaran, 2004a).
} 
maintain its target, which in turn, should bring back the target to its equilibrium level, or at least move it in the direction desired by the policy makers. Though it must be realised, that changes in the target will not always result in changes in the instrument, since the authorities might be willing to wait and see if the target returns back to the equilibrium level on its own. However, over a long enough period where the instrument has changed, one should be able to observe a causal relationship that is two-ways. Specifically, we look at the causal relationship, based on simple Granger Causality tests and the same in ECMs, if the variables are found to be co-integrated, between the CPIX inflation ${ }^{3}$ (target) and the repo rate (instrument) in South Africa, using monthly data over period of 2000:3 to 2007:10. The starting date of the sample is motivated by the fact that South Africa moved to an inflation targeting regime, targeting CPIX inflation, in February of $2000 .{ }^{4}$

At this stage, it is important to lay out the basics of temporal aggregation and systematic sampling - two alternative ways of processing data due to their availability at different frequencies. Specifically, for our case, because CPIX inflation is reported monthly and the repo rate weekly, we must construct a time aggregated series for the repo rate before moving on to the analysis of causality between these two variables. Given this, temporal aggregation simply means aggregating over the four weeks of a month and using the average value as the monthly value corresponding to the monthly value of the CPIX inflation. Systematic sampling, on the other hand, involves using a single observation from the sampling interval, such as the end of the interval observation, which in our case would be the last week of a specific month, to construct the monthly series of the repo rate. Once we have generated the monthly data for the repo rate, either through temporal aggregation or systematic sampling, we can proceed to the analysis of causality between these two variables, first via simple Granger causality tests and then, the same in an ECM framework that allows us to analyse causality by taking explicit account of possible cointegration amongst the two variables. The rest of the paper is organized as follows: Section 2 presents a discussion on the simple Granger causality and the modified version of it in an ECM. Section 3 presents the data, the results, including the tests of stationarity and cointegration, and Section 5 concludes.

\section{Econometric methodology $\mathbf{y}^{5}$}

In this section, we lay out the basics of the standard Granger causality tests and the same in an ECM. The standard Granger causality test examines whether past changes in one variable, $y$, help to explain current changes in another variable, $x$, over and above the information provided by the lagged values of $x$. If not, then one concludes that " $y$ does not Granger cause $x$ ". To determine whether causality runs in the opposite direction, from $x$ to $y$, one basically repeats the experiment, but with

\footnotetext{
${ }^{3} \mathrm{CPIX}$ is CPI excluding mortgage rates .

${ }^{4}$ See Ludi and Ground (2006) for an excellent summary of the history of monetary policy in South Africa.

${ }^{5}$ The discussion in this section depends heavily on Gupta (2004).
}

J.STUD.ECON.ECONOMETRICS, 2009, 33(1) 
the variables interchanged. Four outcomes are feasible: (i) neither variable Granger cause the other; (ii) $y$ causes $x$, but not the other way round; (iii) $x$ causes $y$, but not vice versa; and (iv) $y$ and $x$ Granger cause each other (bi-causality).

Formally, the standard Granger causality test can be represented by the following regression equation:

$\Delta \mathrm{x}_{\mathrm{t}}=\alpha_{0}+\sum_{\mathrm{i}=1}^{\mathrm{m}} \beta_{\mathrm{i}} \Delta \mathrm{x}_{\mathrm{t}-\mathrm{i}}+\sum_{\mathrm{i}=1}^{\mathrm{m}} \delta_{\mathrm{i}} \Delta \mathrm{y}_{\mathrm{t}-\mathrm{i}}+\varepsilon_{\mathrm{t}}$

where

$\Delta$ is the first-difference operator and $\Delta x$ and $\Delta y$ are stationary time series. The null hypothesis that $y$ does not Granger cause $x$ is rejected if the coefficients $\delta_{i}$, in the equation (1) are jointly significant, based on the standard F-test ${ }^{6}$. The null hypothesis that $x$ does not Granger cause $y$ is rejected if the $\beta_{\mathrm{i}}$ are jointly significant in equation (1), when $\Delta y_{t}$ replaces $\Delta x_{t}$ on the left-hand side.

Granger (1983, 1986) and Engle and Granger (1987) provided a more elaborate test of causality, which allows for causality between two variables emerging from a common trend or equilibrium relationship. ${ }^{7}$ Specifically, this alternative to the standard test for the Granger causality considers the possibility that the variable $y$ in its lagged level form, may help to explain the current change in another variable, $x$, even if past changes in $y$ did not. The intuition is that if $y$ and $x$ have a common trend, then the current change in $x$ is partly the fallout of $x$ moving in accordance with the trend value of $y$. Such causality may not be detected by the standard Granger causality test, which only examines whether lagged changes in a variable help to explain current changes in another variable. As with the standard Granger causality test, one may end up having reverse or even two-way causality. Note, as long as $x$ and $y$ have a common trend, causality must exist in at least one direction. The finding of no causality in either direction, as can be observed with the standard Granger causality test, is ruled out when the variables have a common trend.

Formally, this alternative test for Granger causality is based on ECMs that take into account information from the co-integrated properties of time-series variables. Two or more variables, are co-integrated, that is they have an equilibrium relationship, if they share common trend(s). Causality testing, when variables are co-integrated, entails the use of the following ECM:

\footnotetext{
${ }^{6}$ Note an alternative way of looking at the analysis is formulating a restricted model of the following nature: $\Delta \mathrm{x}_{\mathrm{t}}=\alpha_{0}+\sum_{\mathrm{i}=1}^{\mathrm{m}} \beta_{\mathrm{i}} \Delta \mathrm{x}_{\mathrm{t}-\mathrm{i}}+\varepsilon_{\mathrm{t}}$ and then designing the $\mathrm{F}$-statistic $\mathrm{c}_{\mathrm{q}, \mathrm{n}-\mathrm{k}}=\left[\mathrm{SSE}_{\mathrm{R}}-\mathrm{SSE}_{\mathrm{U}}\right)^{*}\{\mathrm{n}-$ $\mathrm{k}\}] /\left[\left(\mathrm{SSE}_{\mathrm{U}}\right)^{*} \mathrm{q}\right]$ by recovering the error sum of squares from the unrestricted, $\mathrm{SSE}_{\mathrm{U}}$ and the restricted, $\mathrm{SSE}_{\mathrm{R}}$ versions of the model concern. Note $\mathrm{q}$ is the number of restrictions imposed with $\mathrm{n}=$ sample size and $\mathrm{k}=$ number of parameters estimated in the unrestricted model.

${ }^{7}$ Such a linkage is particularly important in economics, since it characterizes the long-run equilibrium alignment that persists beyond the short-run dynamic adjustment.
} 
$\Delta \mathrm{x}_{\mathrm{t}}=\alpha_{0}+\sum_{\mathrm{i}=1}^{\mathrm{q}} \beta_{\mathrm{i}} \Delta \mathrm{x}_{\mathrm{t}-\mathrm{i}}+\sum_{\mathrm{i}=1}^{\mathrm{q}} \delta_{\mathrm{i}} \Delta \mathrm{y}_{\mathrm{t}-\mathrm{i}}+\alpha_{1} \mu_{\mathrm{t}-1}+\varepsilon_{\mathrm{t}}$

where

$\mathrm{x}_{\mathrm{t}}$ and $\mathrm{y}_{\mathrm{t}}$ are established first-differenced stationary, co-integrated time series, and $\mu_{t-1}$ is the lagged value of the error term from the following co-integration equation, with an intercept $\mathrm{c}_{0}$ :

$\mathrm{x}_{\mathrm{t}}=\mathrm{c}_{0}+\gamma \mathrm{y}_{\mathrm{t}}+\mu_{\mathrm{t}}$

The inclusion of $\mu_{\mathrm{t}-1}$, which must be stationary if the first-differenced stationary $\mathrm{x}$ and y series are co-integrated, differentiates the ECM from the usual Granger causality regressions. By including $\mu_{\mathrm{t}-1}$, the ECM introduces an additional route through which Granger causality can emerge. Based on equation (2) the null hypothesis that y does not Granger cause $\mathrm{x}$ now, is rejected not only if the $\delta_{\mathrm{i}}$ 's are jointly significant, but also if the coefficient on $\mu_{t-1}$ is significant. Thus, unlike the standard Granger causality test, the error-correction approach as discussed by Granger (1983) allows for the possibility that y Granger causes x, even when the coefficients on lagged changes in y are jointly insignificant. More specifically, the error-correction model helps in capturing the short-run dynamic adjustment of the variables in concern.

\section{Data and results}

In this section, we discuss the data and the results from the simple Granger causality tests and the extended version of it in an ECM, besides the tests of staionarity and co-integration. As discussed at the onset, we are looking at a bivariate framework based on monthly data covering the period of 2000:3 to 2007:10 and involving the CPIX inflation (INFL-CPIX) and the repo rate. All data are obtained from the Quarterly Bulletin of the South African Reserve Bank (SARB). Note given that the repo rate is available at weekly frequencies, we generate a temporally aggregated repo rate series (REPO-AGG) and a repo rate series obtained via systematic sampling (REPO-SYS), where we choose the values of the last week of a particular month as the value of the repo rate for that specific month.

As is standard in time series analysis, we start by studying the time series characteristics of the data. In this regard, we performed tests of stationarity on our variables (INFL-CPIX, REPO-AGG, REPO-SYS) using the Augmented-DickeyFuller (ADF) test, the Dickey-Fuller test with GLS detrending (DF-GLS), the Kwiatkowski, Phillips, Schmidt, and Shin (KPSS) test and the Phillips- Perron (PP) test. As can be seen from Table 1 and Figure 1, the variables were found to follow an autoregressive process with a unit root, as the null hypothesis of a unit root could not be rejected for the variables, expressed in levels for the ADF, the DFGLS and the PP tests, while for the KPSS test, the null hypothesis of stationarity 
was rejected. As the variables were found to be non-stationary, it paved the way for the test for co-integration between INFL-CPIX and REPO-AGG, and INFL-CPIX and REPO-SYS.
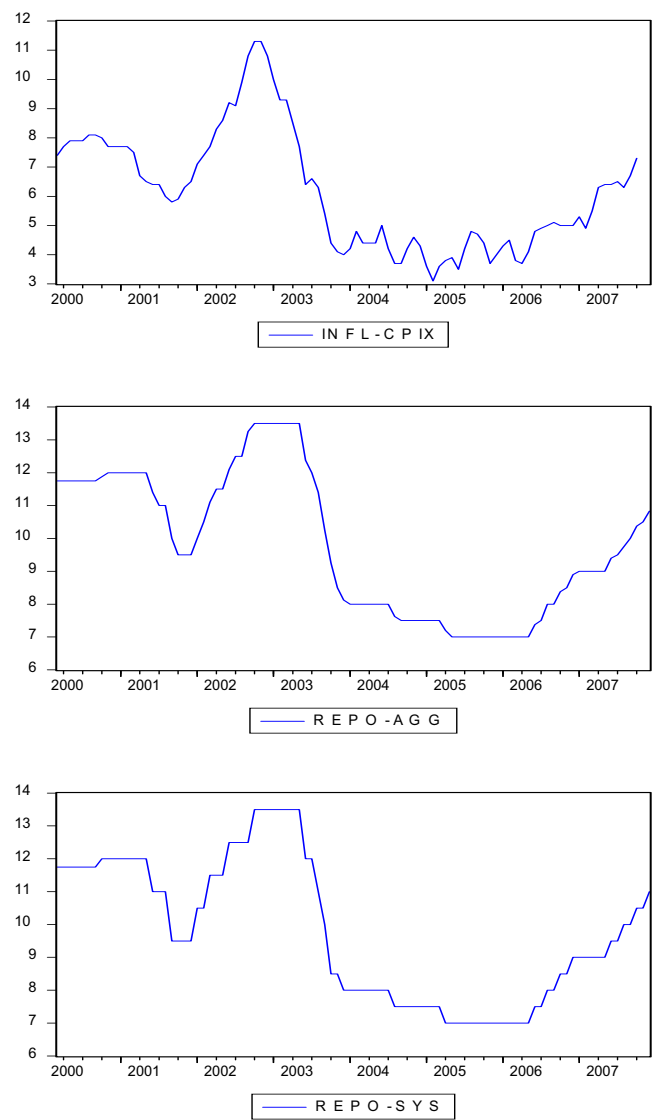

Figure 1: Behaviour of the CPIX inflation and the repo rate

To check whether the above set of variables are co-integrated, we first estimate four set of OLS-regressions between the variables, as in (3), by interchanging the dependent and independent variables ${ }^{8}$, and then checking if the resulting residuals from these regressions are stationary or not. The last four rows of Table 1 reports the stationarity tests of the residuals. Note ECM $\mathrm{i} j \mathrm{j}$ implies the error correction term from the regression of variable $\mathrm{i}=$ INFL-CPIX, REPO-AGG or REPO-SYS on variable $\mathrm{j}=$ INFL-CPIX, REPO-AGG or REPO-SYS, with $\mathrm{i} \neq \mathrm{j}$. As the tests show, all the residuals are stationary, implying that the INFL-CPIX and REPOAGG and INFL-CPIX and REPO-SYS are co-integrated. We also tested for the cointegrating relationship between the variables using the Johansen (1991, 1995) approach. For this, we estimat stable ${ }^{9}$ Vector Autoregressive (VAR) models with 6

${ }^{8}$ The need to run the cointegration equations in both the directions arises from the study by Hendry (1986), who points out that both directions are equally valid apriori.

${ }^{9}$ Stability of the VARs was ensured since no roots were found to lie outside the unit circle. 
and $5 \operatorname{lags}^{10}$ for INFL-CPIX and REPO-AGG, and INFL-CPIX and REPO-SYS respectively, and then allow the level-data to have linear trends, but the co-integrating equations to have only intercepts. Based on the Pantula Principle, both the Trace and the Maximum Eigen Value tests showed that there is one stationary relationship in the data $(\mathrm{r}=1)$ at 5 percent level of significance for both the INFL-CPIX and REPO-AGG and INFL-CPIX and REPO-SYS specifications. The results are reported in Tables 2 and 3.

Table 1: Unit root tests

\begin{tabular}{|c|c|c|c|c|c|c|c|}
\hline \multirow[t]{2}{*}{ Series } & \multirow[t]{2}{*}{ Model } & \multicolumn{2}{|l|}{ ADF } & \multirow{2}{*}{$\begin{array}{l}\text { DF-GLS } \\
\tau_{\tau} \tau_{\mu} \tau\end{array}$} & \multirow{2}{*}{$\begin{array}{l}\text { KPSS } \\
\tau_{\tau} \tau_{\mu} \tau\end{array}$} & \multirow{2}{*}{$\begin{array}{l}\text { PP } \\
\tau_{\tau} \tau_{\mu} \tau\end{array}$} & \multirow[b]{2}{*}{ Conclusion } \\
\hline & & $\tau_{\tau} \tau_{\mu} \tau$ & $\phi_{3} \phi_{2}$ & & & & \\
\hline \multirow[t]{3}{*}{ INFL-CPIX } & $\tau_{\tau}$ & $-2,301451$ & $7,985558^{* * *}$ & $-2,113163$ & 0,562819 & $-1,403788$ & \multirow[t]{3}{*}{$\begin{array}{l}\text { Non- } \\
\text { Stationary }\end{array}$} \\
\hline & $\tau_{\mu}$ & $-2,248787$ & $6,708361^{* * *}$ & $-2,455019$ & 0,120110 & $-1,192604$ & \\
\hline & $\tau$ & $-0,683885$ & & & & $-0,453807$ & \\
\hline \multirow[t]{3}{*}{ D(INFL-CPIX) } & $\tau_{\tau}$ & $-4,441204^{* * *}$ & $10,24079 * * *$ & $-2,232141^{* *}$ & $0,171983^{* * *}$ & $-6,284823^{* * *}$ & \multirow[t]{3}{*}{ Stationary } \\
\hline & $\tau_{\mu}$ & $-4,512120$ & $9,473217^{* * *}$ & $-3,824103^{* * *}$ & $0,126760^{*}$ & $-6,275553^{* * *}$ & \\
\hline & $\bar{\tau}$ & $-4,484333^{* * *}$ & & & & $-6,317933^{* * *}$ & \\
\hline \multirow[t]{3}{*}{ REPO-AGG } & $\tau_{\tau}$ & $-1,970928$ & $21,74644^{* * *}$ & $-1,694095^{*}$ & 0,686636 & $-1,505139$ & \multirow[t]{3}{*}{$\begin{array}{l}\text { Non- } \\
\text { Stationary }\end{array}$} \\
\hline & $\tau_{\mu}$ & $-1,900747$ & $16,32688^{* * *}$ & $-2,124960$ & 0,135452 & $-1,213722$ & \\
\hline & $\tau$ & $-0,418749$ & & & & $-0,472364$ & \\
\hline \multirow[t]{3}{*}{ D(REPO-AGG) } & $\tau_{\tau}$ & $-3,162591^{* *}$ & $14,37207^{* * *}$ & $-3,181413^{* * *}$ & $0,168671^{* * *}$ & $-4,863007^{* * *}$ & \multirow[t]{3}{*}{ Stationary } \\
\hline & $\tau_{\mu}$ & $-3,252642^{*}$ & $9,779662 * * *$ & $-3,256703^{* *}$ & $0,108611^{* * *}$ & $4,956379^{* * *}$ & \\
\hline & $\tau$ & $-3,184169^{* * *}$ & & & & $-4,887813^{* * *}$ & \\
\hline \multirow[t]{3}{*}{ REPO-SYS } & $\tau_{\tau}$ & $-2,033464$ & $6,360373^{* * *}$ & $-1,744080^{*}$ & 0,680410 & $-1,516620$ & \multirow[t]{3}{*}{$\begin{array}{l}\text { Non- } \\
\text { Stationary }\end{array}$} \\
\hline & $\tau_{\mu}$ & $-1,969689$ & $5,165756^{* * *}$ & $-2,205636$ & 0,138958 & $-1,184220$ & \\
\hline & $\tau$ & $-0,397230$ & & & & $-0,445232$ & \\
\hline \multirow[t]{3}{*}{ D(REPO-SYS) } & $\tau_{\tau}$ & $-4,108332$ & $43,48444 * * *$ & $-4,120624$ & $0,175749^{* * *}$ & $-8,704291$ & \multirow[t]{3}{*}{ Stationary } \\
\hline & $\tau_{\mu}$ & $-4,202271$ & $29,23445^{* * *}$ & $-4,191009$ & $0,108571^{* * *}$ & $-8,783028$ & \\
\hline & $\tau$ & $-4,133432 * * *$ & & & & $-8,737819^{* * *}$ & \\
\hline \multirow[t]{3}{*}{$\begin{array}{l}\text { ECM_INFL- } \\
\text { CPIX_REPO-AGG }\end{array}$} & $\tau_{\tau}$ & $-3,266978^{* *}$ & $7,844176^{* * *}$ & $-3,066011^{* * *}$ & $0,105620^{* * *}$ & $-2,801807^{*}$ & \multirow[t]{3}{*}{ Stationary } \\
\hline & $\tau_{\mu}$ & $-3,331011^{*}$ & $5,379915^{* * *}$ & $-3,371398^{* *}$ & $0,063258^{* * *}$ & $-2,837049$ & \\
\hline & $\tau$ & $-3,286629 * * *$ & & & & $-2,816587 * * *$ & \\
\hline
\end{tabular}

\footnotetext{
${ }^{10}$ The optimal lag lengths for the estimated VARs were determined by the Akaike Information Criteria (AIC). Interestingly, the fact that different lag lengths were obtained in the estimated VARs of INFLCPIX and the repo rate derived under alternative forms of aggregation, is not surprising, and has been noted before in the literature by Marcellino (1999).
} 


\begin{tabular}{|c|c|c|c|c|c|c|c|}
\hline \multirow[t]{3}{*}{$\begin{array}{l}\text { ECM_INFL- } \\
\text { CPIX_REPO-SYS }\end{array}$} & $\tau_{\tau}$ & $-2,888377^{*}$ & $8,342721^{* * *}$ & $\overline{2,647032 * * *}$ & $0,105142^{* * *}$ & $-3,106236^{* *}$ & \multirow[t]{3}{*}{ Stationary } \\
\hline & $\tau_{\mu}$ & $-2,912599$ & $4,241666^{* *}$ & $-2,918458^{*}$ & $0,058647 * * *$ & $-3,136704$ & \\
\hline & $\tau$ & $-2,905458^{* * *}$ & & & & $-3,122483^{* * *}$ & \\
\hline \multirow[t]{3}{*}{$\begin{array}{l}\text { ECM_REPO- } \\
\text { AGG_INFL_CPIX }\end{array}$} & $\tau_{\tau}$ & $-3,103991$ & $7,289353^{* * *}$ & $2,651705^{* * *}$ & $0,379768^{*}$ & $-2,759366^{*}$ & \multirow[t]{3}{*}{ Stationary } \\
\hline & $\tau_{\mu}$ & $-3,474149 * *$ & $5,698025^{* * *}$ & $-3,514111^{* *}$ & $0,051985^{* * *}$ & $-2,995492$ & \\
\hline & $\tau$ & $-3,121970^{* * *}$ & & & & $-2,773341^{* * *}$ & \\
\hline \multirow[t]{3}{*}{$\begin{array}{l}\text { ECM_REPO- } \\
\text { SYS_INFL_CPIX }\end{array}$} & $\tau_{\tau}$ & $-2,890546^{*}$ & $8,355255^{* * *}$ & $-2,406527 * *$ & $0,383455^{*}$ & $-3,028010^{* *}$ & \multirow[t]{3}{*}{ Stationary } \\
\hline & $\tau_{\mu}$ & $-3,094328$ & $4,797797 * * *$ & $-3,111639^{* *}$ & $0,048521^{* * *}$ & $-3,259133^{*}$ & \\
\hline & $\tau$ & $-2,907110^{* * *}$ & & & & $-3,044308^{* * * *}$ & \\
\hline
\end{tabular}

Notes: (i) $*(* *)[* * *]$ indicates statistical significance at 10(5)[1] percent level;

(ii) $\tau_{\tau}, \tau_{\mu}, \tau$ indicates the value of the test statistic with intercept and trend, intercept and neither, respectively;

(iii) $\phi_{3}, \phi_{2}$ are the F-statistic of the test regression under the assumptions of intercept and trend and intercept, respectively.

Table 2: Cointegration test results (INFL-CPIX, REPO-AGG)

\begin{tabular}{|c|c|c|c|c|}
\hline Null hypothesis & $\begin{array}{l}\text { Alternative } \\
\text { Hypothesis }\end{array}$ & Test statistic & 0.05 critical value & Prob. ** \\
\hline \multicolumn{5}{|l|}{ Trace Statistic } \\
\hline$R=0$ & $r=1$ & $20,51940 *$ & 15,49471 & 0,0080 \\
\hline$R=1$ & $r=2$ & 2,570264 & 3,841466 & 0,1089 \\
\hline \multicolumn{5}{|c|}{$\begin{array}{l}\text { Trace test indicates } 1 \text { cointegrating eqn(s) at the } 0.05 \text { level. } \\
* \text { denotes rejection of the hypothesis at the } 0.05 \text { level. } \\
\text { **MacKinnon-Haug-Michelis (1999) p-values. }\end{array}$} \\
\hline \multicolumn{5}{|c|}{ Maximum Eigenvalue Statistic } \\
\hline$R=0$ & $r=1$ & $17,94914 *$ & 14,26460 & 0,0125 \\
\hline$R=1$ & $r=2$ & 2,570264 & 3,841466 & 0,1089 \\
\hline
\end{tabular}

Table 3: Cointegration test results (INFL-CPIX, REPO-SYS)

\begin{tabular}{|c|c|c|c|c|}
\hline Null hypothesis & $\begin{array}{l}\text { Alternative } \\
\text { Hypothesis }\end{array}$ & Test statistic & 0.05 critical value & Prob. ** \\
\hline \multicolumn{5}{|c|}{ Trace Statistic } \\
\hline$R=0$ & $r=1$ & $19,88720^{*}$ & 15,49471 & 0,0102 \\
\hline$R=1$ & $r=2$ & 3,720587 & 3,841466 & 0,5370 \\
\hline \multicolumn{5}{|c|}{$\begin{array}{l}\text { Trace test indicates } 1 \text { cointegrating eqn(s) at the } 0.05 \text { level. } \\
* \text { denotes rejection of the hypothesis at the } 0.05 \text { level. } \\
* * \text { MacKinnon-Haug-Michelis (1999) p-values. }\end{array}$} \\
\hline \multicolumn{5}{|c|}{ Maximum Eigenvalue Statistic } \\
\hline$R=0$ & $r=1$ & $16,16661^{*}$ & 14,26460 & 0,0247 \\
\hline$R=1$ & $r=2$ & 3,720587 & 3,841466 & 0,5370 \\
\hline
\end{tabular}


We start by looking at simple Granger causality tests for the CPIX inflation and the repo rate ${ }^{11}$, aggregated either via temporal aggregation or systematic sampling. As can be seen from models (a) and (b) in Table 4, in case of temporal aggregation, causality runs in only one direction from the target to the instrument. On the other hand, with systematic sampling, i.e., models (c) and (d), we observe bidirectional causality between INFL-CPIX and REPO-SYS. This is exactly what Abeysinghe and Gulasekaran (2002, 2004a and 2004b) and Gulasekaran (2004) pointed to in their studies. Though ideally in an inflation targeting framework, we would want to ensure that causality between the target and the instrument runs both ways, recall that the authors warned against the possibility of bidirectional causality between cointegrated variables with systematic sampling, when actually causality is unidirectional. So at this stage, purely based on Abeysinghe and Gulasekaran (2002 and 2004a and 2004b) and Gulasekaran (2004), we would want to believe that more reliance should be placed on the causality results obtained with temporal aggregation. Interestingly, this result has serious implications for South Africa's inflation targeting framework, since it suggests that the transmission mechanism, whatever it might be that causes the repo rate to affect the target, is not working properly. Before we discuss the validity of the above set of results, we also check the robustness of these results econometrically, by moving onto an ECM and testing for Granger causality.

\section{Table 4: Standard Granger causality tests}

\begin{tabular}{|c|c|c|c|}
\hline \multicolumn{2}{|c|}{ Model } & F-statistic & Inference \\
\hline (a) & DINFL-CPIX, DREPO-AGG & 0,61384 & REPO-AGG does not Granger cause INFL-CPIX \\
\hline (b) & REPO-AGG, DINFL-CPIX & $3,96904 * * *$ & INFL-CPIX Granger cause REPO-AGG \\
\hline (c) & DINFL-CPIX, DREPO-SYS & $2,28607 *$ & REPO-SYS Granger cause INFL-CPIX \\
\hline (d) & DREPO-SYS, DINFL-CPIX & $6,83711 * * *$ & INFL-CPIX Granger cause REPO-SYS \\
\hline \multicolumn{4}{|c|}{$\begin{array}{l}\text { Notes: } \\
\text { (i) Ordering is such that the first variable indicates the dependent variable; } \\
\text { (ii) } \quad *(* *)[* * *] \text { indicates statistical significance at } 10(5)[1] \text { percent level. }\end{array}$} \\
\hline
\end{tabular}

Remembering that in an ECM, the null hypothesis that a variable y does not Granger cause $\mathrm{x}$, requires not only the differenced lagged values of $\mathrm{y}$ to be jointly insignificant, but also the error correction term to be insignificant. Given this, from Table 5 we see that the basic conclusion of bidirectional causality between INFLCPIX and REPO-SYS still holds for the systematically sampled data. However, with temporally aggregated repo rate, we now find that causality runs only in one direction with REPO-AGG Granger causing INFL-CPIX - a result opposite of what was obtained in Table 4 under the simple tests of Granger causality. This result, perhaps, puts the findings of Mamingi (1996) into perspective the best. Recall, the author had indicated that Granger causality tests in Error Correction Models (ECMs) with temporally aggregated data is flawed, but with systematic sampling, for variables that are co-integrated, Granger causality distortion is largely

\footnotetext{
${ }^{11}$ As with the cointegration tests, the optimal lag lengths for Granger Causality tests between INFLCPIX and REPO-AGG and INFL-CPIX and REPO-SYS were determined by the AIC, obtained by estimating the corresponding bivariate VARs. The test suggested the use of 8 lags for the model with the aggregated data, and 4 for the systematically sampled data.
} 
absent. Hence, now based on the Granger causality tests from the ECMs, a researcher would be more prone to believe that the causal relationship between the target and the instrument is actually bidirectional.

Table 5: Granger causality tests in ECMs

\begin{tabular}{l|l|l|l}
\hline Model & F-statistic & t-statistic & Inference \\
\hline (a) DINFL-CPIX, DREPO- & 0,707740 & $-1,811247^{*}$ & DREPO-AGG Granger cause DINFL-CPIX \\
AGG, ECM_INFL- & & & \\
CPIX_REPO-AGG(-1) & & & \\
\hline (b) DREPO-AGG, DINFL- & 1,192738 & $-1,502515$ & $\begin{array}{l}\text { DINFL-CPIX does not Granger cause } \\
\text { DREPO-AGG }\end{array}$ \\
CPIX, ECM_REPO- & & & DREPO-SYS Granger cause DINFL-CPIX \\
AGG_INFL-CPIX(-1) & & $-1,911047^{*}$ & \\
(c) DINFL-CPIX, DREPO- & $2,435239^{*}$ & & DINFL-CPIX Granger cause DREPO-SYS \\
SYS, ECM_ INFL- & & & \\
CPIX_REPO-SYS(-1) & & & \\
(d) DREPO-SYS, DINFL- & 1,779417 & $-3,164446 * * *$ & \\
CPIX, ECM_REPO- & & \\
SYS_INFL-CPIX(-1) & Notes: \\
(i) Ordering is such that the first variable indicates the dependent variable; \\
(ii) *(**)[**] indicates statistical significance at 10(5)[1] percent level.
\end{tabular}

So in summary, we find that with the repo rate temporally aggregated, simple Granger causality tests suggests that the causality runs from the inflation rate to the repo rate, while the Granger causality tests in the ECM indicates the opposite, i.e., the repo rate is found to Granger cause inflation. However, with the systematically sampled repo rate, both the simple and the extended version of the Granger causality tests, suggested bi-directional causality. The most important question now is: What really is the direction of the causal relationship between the two variables in concern? To draw our conclusions let us try and analyse the relationship between the two variables purely from an economic point of view.

As Figure 1 indicates, the repo rate, whether obtained via temporal aggregation or systematic sampling, moves in accordance with the CPIX inflation, hence, the fact that they were found to be co-integrated is not at all surprising. However, from the figure it is difficult to decipher the direction of causality. For this purpose, we decided to look at the data of the variables. Note, initially after South Africa decided to adopt an inflation targeting regime with a target band of 3 percent to 6 percent, inflation rate stayed above the target band for until the eighth month of 2003. This however, is not surprising since most likely the SARB was building credibility over this period. Once the economic agents realised that the SARB was serious about price stability, the inflation rate stayed within the band until the third month of 2007, and the SARB was able to continuously stay within the target via the changes in its instrument. Only recently has the inflation rate gone beyond the target band, and this is most likely due to the hikes in oil prices. It would be irrational to believe that the CPIX inflation stayed within the target for nearly four years because economic conditions were favourable through out this period. The reason for it being unlikely is because, given that South Africa is a small open economy, it is affected not only by domestic shocks but regularly by external 
shocks of different nature. Hence, it must be that the repo rate was able to respond to the inflationary pressures, and the CPIX inflation, in turn, responded to the repo rate. So based on the economic events, we are more prone to conclude that the direction of causality between our two chosen variables is bi-directional. And, in this case, it happens that the causality tests carried out with the systematically sampled data most likely draws the correct conclusions. However, it must be emphasized that under a different situation, i.e., with a different set of variables, it is not at all impossible that causal inferences based on temporally aggregated data might be the appropriate one. But, we believe that given that an economic system is ideally described by a general equilibrium framework, it is more likely for the variables in the system to affect each other and, in turn, be affected by them.

\section{Conclusions}

While on one hand studies like Sims (1971), Tiao and Wei (1976), Wei (1982), Cunningham and Vilasuso (1995), Cunningham and Vilasuso (1997) and Mamingi (1996) tend to prefer systematic sampling when analysing causality, more recent papers by Abeysinghe and Gulasekaran (2002, 2004a and 2004b) and Gulasekaran (2004) on the other hand, suggests that systematic sampling tend to induce spurious causality. Against such a backdrop, we try and investigate if such contradictions regarding the direction of causality depending on the two alternative ways of processing the data can be resolved by falling back on the economic theory that possibly governs the relationship between these two variables.

To validate our point we look at the relationship between a nominal target and the monetary instrument used to achieve this target. We indicate that, though there is no denying the importance of econometric theory and the role that Monte Carlo simulations play in enforcing such theories, it is perhaps, worthwhile to fall back upon the data in itself and analyse it from the perspective of economic theory/intuition, and economic conditions prevailing in the economy over the specific period in question, as a source of second opinion. However, we realise that such an approach might become exceedingly difficult as the number of variables increases. Thus, we suggest that given the general equilibrium structure of the economic system, it is perhaps, much well-served to answer such questions using estimated versions of dynamic (stochastic) general equilibrium frameworks, which apriori allows for the variables in the system to affect others and, in turn, get affected by them. We feel that this is the way forward, because the economy is far too complicated for Granger causality tests with temporally aggregated data or systematically sampled data to address causal relationships between variables of interest.

\section{References}

Abeysinghe, T and Gulasekaran, R (2002): "The Distortionary Effects of Temporal Aggregation on Granger Causality", Departmental Working Papers wp0204, National University of Singapore, Department of Economics.

Abeysinghe, T and Gulasekaran, R (2004a): "Temporal Aggregation, Causality Distortions, and a Sign Rule", Departmental Working Papers wp0406, National University of Singapore, Department of Economics. 
Abeysinghe, T and Gulasekaran, R (2004b): "The Consequences of Systematic Sampling on Granger Causality”, Econometric Society 2004 Australasian Meetings 250, Econometric Society.

Cunningham, S R and Vilasuso, R J (1995): "Time Aggregation and Causality Tests: Results from a Monte Carlo Experiment", Applied Economics Letters, 2(10), 403-405.

Cunningham, S R and Vilasuso, R J (1997): "Time Aggregation and the Money-Real Output Relationship", Journal of Macroeconomics, 19(4), 675-695.

Engle, R F. and Granger, C W J (1987): "Co-integration and Error-Correction: Representation, Estimation, and Testing”, Econometrica, 55(2), 251-276.

Granger, C W J (1983): “Co-integrated Variables and Error-Correction Models”, Working Paper 8313, University of California, San Diego.

Granger, C W J (1986): "Developments in the Study of Co-integrated Economic Variables", Oxford Bulletin of Economics and Statistics, 48(3), 213-228.

Gulasekaran, R (2004): "Impact of Systematic Sampling on Causality in the Presence of Unit Roots", Economic Letters, 84(1), 127-132.

Gupta, R (2004): "Revisiting the Temporal Causality between Money and Income", The Indian Economic Journal, 52(1-2), 33-45.

Ludi, K L and Ground, M (2006): "Investigating the Bank-Lending Channel in South Africa: A VAR Approach”, Working Paper No. 2006-04, Department of Economics, University of Pretoria.

Mamingi, N (1996): "Aggregation Over Time, Error Correction Models and Granger Causality: A Monte Carlo Investigation”, Economic Letters, 52(1) 7-14.

Sims, C A (1971): "Discrete Approximations to Continuous Time Distributed Lags in Econometrics," Econometrica, 39(3) 545-563.

Tiao, G C and Wei, W S (1976): "Effects of Temporal Aggregation on the Dynamic Relationship between Two Time Series Variables”, Biometrica, 63(3) 513-523.

Wei, W S (1982): “The Effects of Systematic Sampling and Temporal Aggregation on Causality-A Cautionary Note”, Journal of the American Statistical Association, 77(378), 316-319. 